\title{
Geospatial analysis of relationship between climate factors and diffusion of air pollution in Chiang Mai, Thailand
}

\author{
Supachai Nakapan ${ }^{\mathrm{a}, \mathrm{c}, *}$, Supab Choopun ${ }^{\mathrm{a}, \mathrm{b}, \mathrm{c}}$ \\ a Department of Physics and Materials Science, Faculty of Science, Chiang Mai University, \\ Chiang Mai 50200 Thailand \\ b Applied Physics Research Laboratory, Department of Physics and Materials Science, Faculty of Science, \\ Chiang Mai University, Chiang Mai 50200 Thailand \\ c Research Center in Physics and Astronomy, Chiang Mai University, Chiang Mai 50200 Thailand
}

*Corresponding author, e-mail: snakapan@gmail.com

\begin{abstract}
Geospatial analysis is applied to find a relationship between climate factors (relative humidity and temperature) and air pollutants (PM10 and CO) from January to May 2012-2014, the period when Chiang Mai province, northern part of Thailand, was covered with haze episode. Air pollutants and climate factors data were obtained from air monitoring stations of the Pollution Control Department. Temporal and spatial distribution of air pollutants and climate factors were analysed by Inverse Distance Weight techniques in ARCGIS. Correlation between air pollutants (PM10 and CO) and climate factors (relative humidity and temperature) were also investigated. The results showed that temporal trend of PM10 and CO were similar, they were high during February to April. Low level of relative humidity was observed during February to April, while high temperature was found in March and April. When the relative humidity decreased, the PM10 increased especially in the northern part of Chiang Mai with high correlation $\left(R^{2}=0.83,0.66,0.73\right)$. On the other hand, when high moisture (\%RH) covered almost Chiang Mai area during January 2012 and May 2013, the PM10 was decreased, and low correlation between the PM10 and the temperature was observed $\left(R^{2}=0.01,0.01,0.04\right)$. Distribution of CO covered in the area during March and April was similar to PM10, however, it was higher in the central and the northern part of Chiang Mai. High correlation between $\mathrm{CO}$ and relative humidity was found $\left(R^{2}=0.90,0.02,0.92\right)$, whereas low relationship between $\mathrm{CO}$ and temperature was observed.
\end{abstract}

KEYWORDS: ARCGIS, relative humidity, temperature, haze episode

\section{INTRODUCTION}

Geospatial analyses are primarily used to describe a spatial patterns, predicting a patterns, and testing hypothesis based on interpolation or mapping ${ }^{1}$. A clear picture of the periodical changes in time as well as the diffusion map of air pollutants through a region level have been presented ${ }^{2}$. A geospatial maps can be used as a tool to alert or notify people who reside in the hazardous air pollutants areas. In addition, the map of pollutant distribution can be used by the decision makers to implement the mitigation measures.

In Thailand, the total amount of air pollutants was significant in north-eastern, northern areas, the central and southern areas as a result of burning of agriculture residues ${ }^{3}$. In northern, mountainous areas broadly covered by natural forest were faced with severe haze episodes during summer every year since the last decade. Particulate matter (PM10) concentrations are high in the dry season and always highest in March, then are low again in the rainy season, after that it is constant for about 6 months (May-October). The PM10 increases again during the beginning of the dry season (November) due to low precipitation and starting of open burning in agricultural areas during harvesting season in November to December ${ }^{4}$. Particles emitted from biomass burning were those particulates responsible for PM10 episodic pollution in Chiang Mai Basin because of the concentrations of glycerol and erythritol during the episodic pollution were much higher than during the non-episodic pollution ${ }^{5}$. After PM10 dispersed to the atmosphere, it affects the environment including plants, animals, and human. 
The study of an effect of PM10 on peak expiratory flow rates (PEFR) showed that PM10 were consistently positively associated with the event of PEFR ${ }^{6}$. Previous study reported that a spatial correlation of PM10 and respiratory disease was high in the 2nd week of March in 2007 in the north and northeast of Chiang Mai, and increasing of PM10 was associated with an emergency visit of COPD and asthma ${ }^{7}$. The highest of a very unhealthy level of PM10 in February 2011 and February 2012, and the highest concentration of PM10 were found in 2010, 2011, and 2012 in Chiang Mai area ${ }^{8}$.

Air quality is influenced not only by how much pollution is emitted into the air, but also the meteorological and topographical factors as well ${ }^{9}$. Meteorological conditions were the primary factor determining day-to-day variations in pollutant concentrations, its factors affect the dilution, diffusion and accumulation of the pollutants even in the same condition of pollutant sources, the dominant meteorological factors influencing the atmospheric pollution were different in each season ${ }^{10,11}$. Meteorology and emission were interrelated and both play important roles in the Chiang Mai haze episode formation by the local emission sources including open biomass burning and seasonal industries which were found to be highest during March. Meteorological parameters such as precipitation and relative humidity as well as scale of open burning derived from number of hotspots were found to be the most influential factors and potential source of ambient PM10. The stable atmosphere associated with anticyclone systems (inversion, weak wind) limits the pollutant dispersion both in vertical and horizontal directions. Chiang Mai is a mountain-valley topographical type which limits the dispersion of air. The highest PM10 level in $24 \mathrm{~h}$ was associated with the condition of weak wind and strong inversion during March and April in $2001-2008^{12}$. This study aims to determine a correlation between air pollutants (PM10 and $\mathrm{CO}$ ) and climate factors (relative humidity and temperature) in 2012-2014, and the comparison of the results with the previous study at Chiang Mai province. Investigating of a spatial and temporal variations of the air pollutants and climate factors were also analysed using a geospatial technique.

\section{MATERIALS AND METHODS}

\section{Study area}

Chiang Mai province, located between latitude $17^{\circ} 25^{\prime} \mathrm{N}-20^{\circ} 15^{\prime} \mathrm{N}$ and longitude $98^{\circ} 00^{\prime} \mathrm{E}-$ $99^{\circ} 58^{\prime} \mathrm{E}$ (UTM: $390000 \mathrm{E}-560000 \mathrm{E}, 1900000 \mathrm{~N}-$

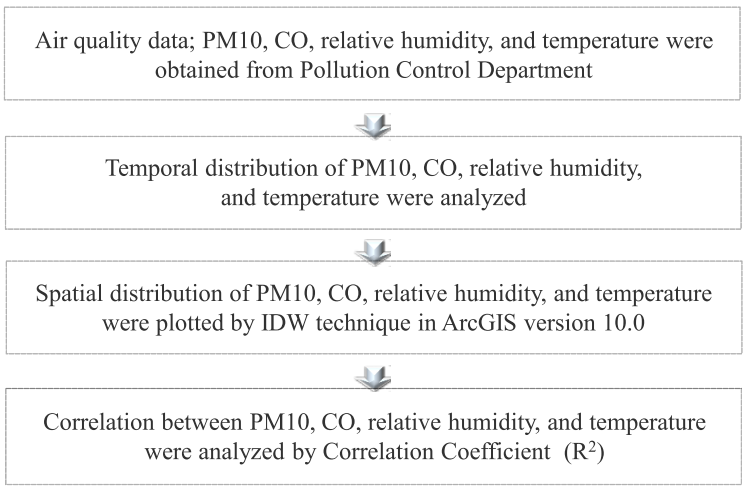

Fig. 1 Method flowchart.

$2230000 \mathrm{~N}$ ), it is the biggest province in the northern part of Thailand covering an area of $22061 \mathrm{~km}^{2}$. Its terrain mostly consists of forested mountains with an average elevation of $310 \mathrm{~m}$ above mean sea level which generally run through the province in a north to south pattern. Its population is around 1.7 million people distributed among 24 administrative districts.

\section{Data}

Daily information of PM10, CO, relative humidity (\%RH) and temperature (Temp) between JanuaryMay 2012-2014 was obtained from 12 air monitoring stations located in Chiang Mai, Chiang Rai, Phayao, Lamphun, Mae Hong Son, Phrae, Nan, and Lampang provinces under the Thailand Pollution Control Department, and were averaged on monthly basis to prepare the spatial analysis.

\section{Methods}

The temporal graph and spatial distribution map of PM10, CO, relative humidity, and temperature were plotted to explain the relationship between air pollutants and climate factors using inverse distance weight (IDW) techniques in ARCGIS version 10.0; it is assumed substantially that the rate of correlations and similarities between neighbours is proportional to the distance between them that can be defined as a distance reverse function of every point from neighbouring points ${ }^{13}$ using equation

$$
\hat{V}=\frac{\sum_{i=1}^{n} \frac{V_{i}}{d_{i}}}{\sum_{i=1}^{n} \frac{1}{d_{i}}},
$$

where $\hat{V}$ is the unknown point, $v_{i}$ is the known point, and $d_{i}$ is the distance from known to unknown point. The correlation value $\left(R^{2}\right)$ between 
Table 1 Relationship between air pollutants (PM10, CO) and climate (\%RH, Temp).

\begin{tabular}{cccccc}
\hline \multirow{2}{*}{ Year } & \multicolumn{5}{c}{ Correlation coefficient $\left(R^{2}\right)$} \\
\cline { 2 - 6 } & PM-CO & PM-\%RH & PM-Temp & CO-\%RH & CO-Temp \\
\hline 2012 & 0.84 & 0.83 & 0.01 & 0.90 & 0.05 \\
2013 & 0.39 & 0.66 & 0.01 & 0.02 & 0.13 \\
2014 & 0.87 & 0.73 & 0.04 & 0.92 & 0.09 \\
\hline
\end{tabular}

PM10, CO, and relative humidity and temperature were analysed in excel.

Fig. 1 shows a method flowchart of this study, starting from data collection, temporal and spatial as well as correlation analysis.

\section{RESULTS AND DISCUSSION}

Smoke haze problem in the upper northern part of Thailand including Chiang Mai province always occurs during February-April, therefore, this study intended to investigate the distribution of air pollutants and its correlation with climate factors in this critical period by focusing on the two air pollutants; particulate matter (PM10) and CO, and the two climate factors; relative humidity ( $\% \mathrm{RH})$ and temperature (Temp). Fig. 2 shows temporal distribution of PM10, \%RH, Temp, and CO during January-May 2012-2014 obtained from the two air monitoring stations in Chiang Mai province, Chiang Mai City Hall (Station 1) and Yupparaj Wittayalai School (Station 2). PM10 trend from the two monitoring stations were similar, it was raised in February, highest in March, and decreased to the normal level in May. As with the pattern of $\mathrm{CO}$ which also increased in the same period, because these two air pollutants were produced from open burning of agriculture sector to prepare the field for the next cultivation in areas of Chiang Mai, nearby province, as well as neighbour country (Myanmar). While relative humidity was low in February-April, lowest in March, and increased again in May, temperature was high in March-April, and highest in April which is the hottest month for Thailand.

Fig. 3 shows spatial distributions of PM10, $\% \mathrm{RH}$, Temp and $\mathrm{CO}$ which were analysed by IDW technique in ARCGIS 10. Table 1 indicated a correlation $\left(R^{2}\right)$ between air pollutants (PM10, CO) and climate factors (\%RH, Temp). This study shows a high correlation between PM10 and CO $(0.84$ and 0.87) in 2012 and 2014 because these two air pollutants are directly released from biomass and agricultural residual burning especially during incomplete combustion.

\section{Distribution of PM10 and its correlation with climate factors}

Spatial distributions of PM10 during February-April were higher than during January and May, and was peak in March, especially in the northern part of Chiang Mai connected to Chiang Rai and near Myanmar, neighbouring country which faced to the same haze episode. The PM10 hazard map almost dominated in the north areas of Chiang Mai through 4 weeks of March $2007^{14}$. Furthermore, the PM10 concentration in this period was higher than the limit set by the Thai national ambient air quality standards $\left(120 \mu \mathrm{g} / \mathrm{m}^{3}\right)$ especially in March 2013 . There was remarkable seasonal variations in PM10 concentrations which were very high during the dry season of the summer monsoon ${ }^{15}$. In the dry season, air pollution is a main issue because the low air-flow and inversion temperatures cause a high accumulation of air pollutants ${ }^{4}$, and high atmospheric stability during summer also was another main factor triggering heavy air pollution ${ }^{16}$.

\section{Correlation between PM10 and relative humidity}

In March 2013, a spatial distribution of relative humidity showed low level of moisture in the air, the condition which related to increasing of PM10 distribution in the northern part of Chiang Mai. On the other hand, when high moisture level covered almost Chiang Mai area during January 2012 and May 2013, low concentration of PM10 in all areas was observed because high relative humidity caused hygroscopic growth of the particles, leading to large particles, and removal of particles due to dry deposition ${ }^{17-19}$. The highest moisture content with updraft conditions associated with this pattern would enhance the vertical dispersion of air pollution $^{12}$. Those spatial results could be well supported by high correlation coefficients of PM10 and \%RH; $0.83,0.66$, and 0.73 , respectively shown in this study. In addition, a higher PM10 concentration and a lower relative humidity together aggravated the effects of PM on respiratory-related hospital admissions, while decreasing relative humidity was also a predictor of increased respiratory-related hospital admissions ${ }^{20}$. The knowledge from this study could be beneficial to the decision makers to monitor confounding climate factors which affect air pollution distribution in order to prevent or give warning to the population in the risk area. 

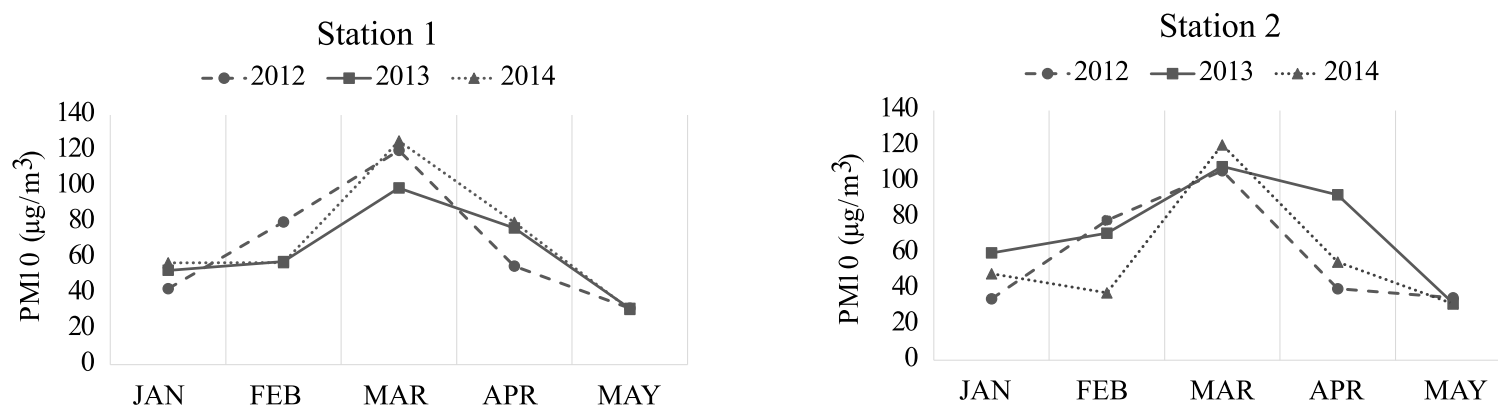

Station 1
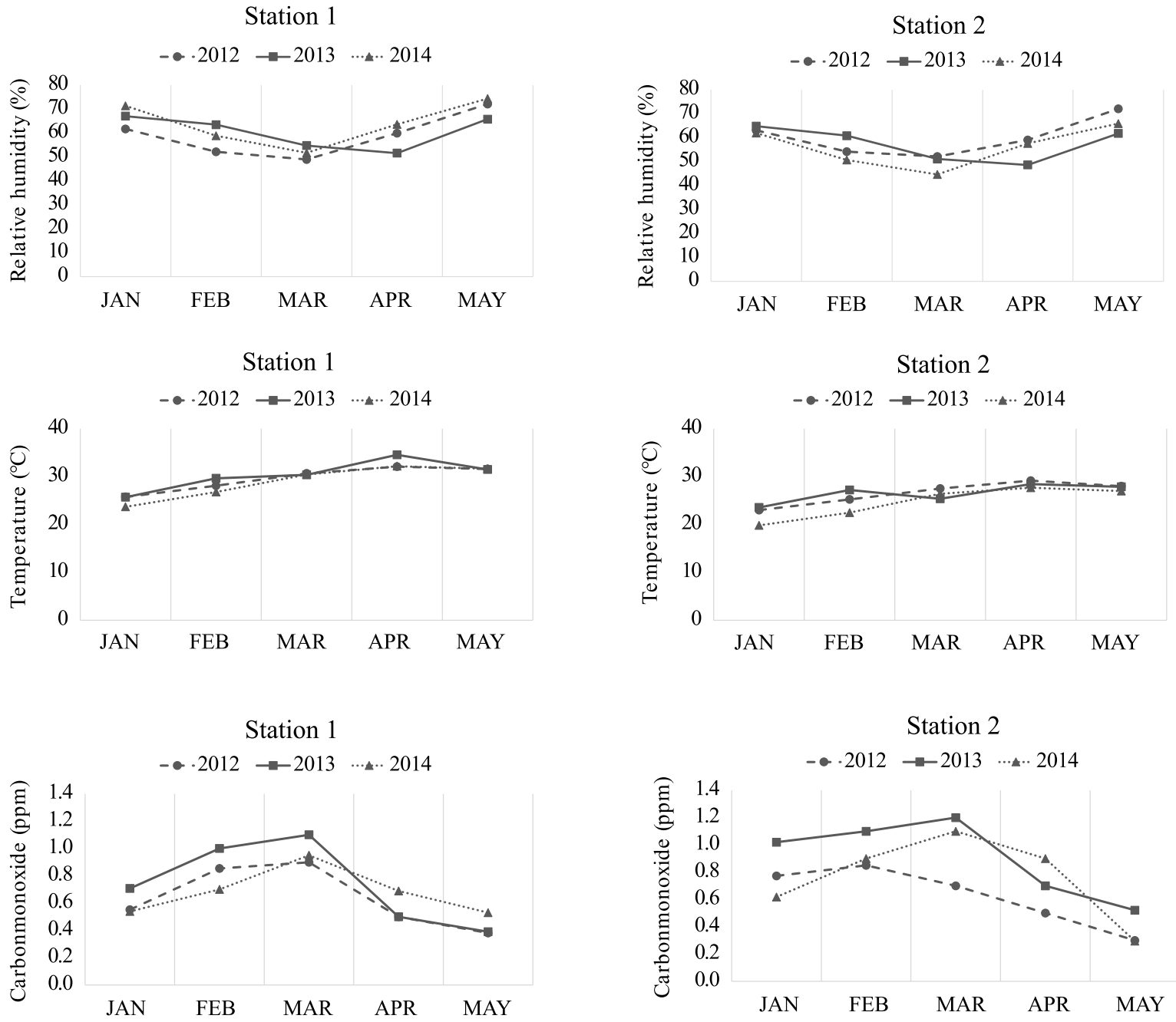

Fig. 2 Temporal distribution of PM10, \%RH, Temp, and CO of the two air monitoring stations; Chiang Mai City Hall (Station 1) and Yupparaj Wittayalai School (Station 2), during 2012-2014.

\section{Correlation between PM10 and temperature}

High temperature was found in the central of Chiang Mai, and lower in northern part during March and April every year. The correlation coefficients between PM10 and temperature during 2012-2014 were $0.01,0.01$, and 0.04 , respectively. This is not quite correlated. PM10 concentrations are not always directly related to temperature for the long-term component whereas the coefficients for 


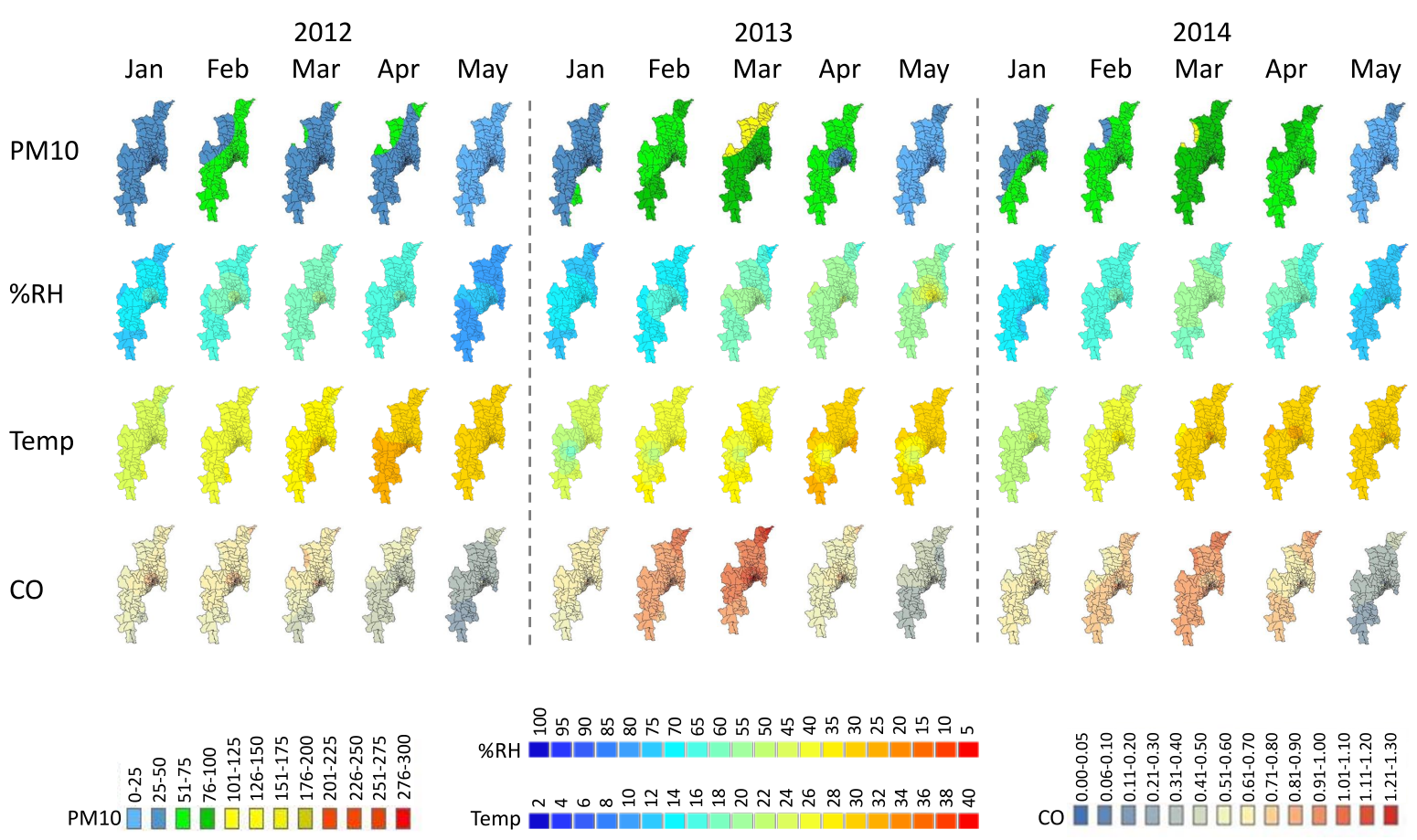

Fig. 3 Spatial distribution of PM10, \%RH, Temp, and CO in Chiang Mai province during 2012-2014.

temperature are negative ${ }^{21}$. Temperature did not have a significant effect on PM10 concentrations, but the best correlation was obtained with relative humidity ${ }^{22}$. The concentration of PM10 was better correlated with the geopotential heights than with their temperatures. Stronger dilution effect due to higher temperature and mixing layer height in the summer lead to lower PM10 concentrations ${ }^{23}$, and high PM10 pollution events are more associated with meteorological conditions of no precipitation and moderate temperature ${ }^{19}$.

\section{Distribution of CO and its correlation with climate factors}

Distribution of CO, similar to PM10, was clearly high during February-April, and highest in March 2013, then decrease in May. These could be assumed that high contribution of $\mathrm{CO}$ emissions might be released from biomass and crop residue burning over these areas during February-April. More extensive biomass burning activities over the southeast Asian continent were observed in March, likely resulting in higher $\mathrm{CO}$ and $\mathrm{O}_{3}$ concentrations ${ }^{24}$. CO was evenly diffused to all study areas, however it still higher in the central and the northern part than the other area of Chiang Mai. However, concentration of CO in Chiang Mai was not exceed the Thai national ambient air quality standards $(9 \mathrm{ppm} / 8 \mathrm{~h})$. The relative contributions of $\mathrm{CO}$ source areas in terms of biomass burning, anthropogenic activities, and oceanic production, during the expedition, 54\% of the $\mathrm{CO}$ from biomass burning originated from wild fires ${ }^{25}$. CO is a colourless, but poisonous and odorless gas. Its largest sources come from vehicles, especially when they are moving slowly ${ }^{26}$, therefore, CO could affect public health when its concentration rises above the standard of air quality.

\section{Correlation between $\mathrm{CO}$ and relative humidity}

Correlation $\left(R^{2}\right)$ between CO and relative humidity during 2012-2014 were 0.90, 0.02, and 0.92, respectively. The relationships between PM2.5, PM10, $\mathrm{CO}, \mathrm{SO}_{2}, \mathrm{NO}_{2}$ and $\mathrm{O}_{3}$ and meteorological parameters (temperature, and relative humidity, wind direction, wind speed) in 2013-2014 showed that the concentrations of PM2.5, PM10, $\mathrm{CO}, \mathrm{SO}_{2}$, and $\mathrm{NO}_{2}$ were positively correlated with relative humidity in all seasons. The data were similar to our study except in 2013, whereas CO concentration directly proportional to a power of humidity ${ }^{27}$. However, previous study reported a negative correlation between meteorology and $\mathrm{CO}, \mathrm{NO}_{\mathrm{x}}$, and $\mathrm{O}_{3}$, the relative humidity of which was weakly linked to all pollutants $(p<0.01)^{28}$. Hence a longer period of 
study (year) should be included in further study to verify a correlation between $\mathrm{CO}$ and relative humidity.

\section{Correlation between $\mathrm{CO}$ and temperature}

As mentioned above, high temperature and high $\mathrm{CO}$ distribution were found in the central part of Chiang Mai in 2012-2013. High concentration of CO was found in March and April in 2013-2014, but low relationship between $\mathrm{CO}$ and temperature $(0.05,0.13$, and 0.09 , respectively) was observed. The low correlation between $\mathrm{CO}$ and temperature $\left(R^{2}=0.39,0.19,0.03\right)$ in summer was found in Beijing, Shanghai, and Guangzhou, respectively ${ }^{29}$.

Table 1 shows a correlation $\left(R^{2}\right)$ between air pollutants (PM10, CO) and climate factors (\%RH, Temp). A positive correlation trend between PM10 and $\mathrm{CO}$, and PM10 with relative humidity were high, whereas a negative correlation between PM10 and temperature was found. For $\mathrm{CO}$, there was positive correlation with relative humidity, but not temperature as discussed previously.

\section{CONCLUSIONS}

The temporal and spatial distribution of PM10, CO, $\% \mathrm{RH}$, and temperature of Chiang Mai province between January-May 2012-2014 were analysed by ARCGIS 10. PM10 concentration and CO peaked in March every year, while \%RH was low in MarchApril. Temperature was high during March-April, especially in the central of Chiang Mai. Spatial distribution map showed that the northern part of Chiang Mai was the critical area affected by PM10 and CO. High temperature was observed in the middle part of study area. The correlation analysis $\left(R^{2}\right)$ showed that PM10 was related to relative humidity; when relative humidity increased, PM10 decreased. The correlation coefficients between PM10 and \%RH were $0.83,0.65$, and 0.73 , while the $R^{2}$ between PM10 and CO were 0.84 and 0.87, but there was relatively low correlation between PM10 and temperature. The correlation result might be impact during the period of study (3 years), but the data might not be enough to observe the trend of correlation between air pollutants and climate factors. Further studies taking longer study period, and including other climate factors such as wind speed, wind direction, mixing height, should be carried out to find the accurate value or trend of correlation between air pollutants and climate factors. Nevertheless, other areas in the northern part of Thailand which received an impact from PM10 should also be considered to study.

Acknowledgements: This work was supported by the Chiang Mai University Research Grant. We would like to thank Thailand Pollution Control Department for supporting air pollution and meteorology data.

\section{REFERENCES}

1. Moise IK, Cunningham M, Inglis A (2015) Geospatial analysis in global health M\&E: A process guide to monitoring and evaluation for informed decision making. MEASURE Evaluation, North Carolina.

2. Hysenaj M (2016) Geospatial analysis of environment pollution. $J$ Ecol Eng 17, 10-7.

3. Phairuang W, Hata M, Furuuchi M (2017) Influence of agricultural activities, forest fires and agroindustries on air quality in Thailand. $J$ Environ $S c i$ 52, 85-97.

4. Wiriya W, Prapamontol T, Chantara S (2013) PM10bound polycyclic aromatic hydrocarbons in Chiang Mai (Thailand): Seasonal variations, source identification, health risk assessment and their relationship to air-mass movement. Atmos Res 124, 109-22.

5. Tsai TI, Sopajaree K, Chotruksa A, Wu HC, Kuo SC (2013) Source indicators of biomass burning associated with inorganic salts and carboxylates in dry season ambient aerosol in Chiang Mai Basin, Thailand. Atmos Environ 78, 93-104.

6. Wiwatanadate P, Liwsrisakun C (2011) Acute effects of air pollution on peak expiratory flow rates and symptoms among asthmatic patients in Chiang Mai, Thailand. Int J Hyg Environ Health 214, 251-7.

7. Pothirat C, Tosukhowong A, Chaiwong W, Liwsrisakun C, Inchai J (2016) Effects of seasonal smog on asthma and COPD exacerbations requiring emergency visits in Chiang Mai, Thailand. Asian Pac $J$ Allergy Immunol 34, 284-9.

8. Suwanprasit C, Charoenpanyanet A, Pardthaisong L, Sinampol P (2018) Spatial and temporal variations of satellite-derived PM10 of Chiang Mai: An exploratory analysis. Procedia Eng 212, 141-8.

9. Unal YS, Toros H, Deniz A, Incecik S (2011) Influence of meteorological factors and emission sources on spatial and temporal variations of PM10 concentrations in Istanbul metropolitan area. Atmos Environ 45, 5504-13.

10. He J, Gong S, Yu Y, Yu L, Wu L, Mao H, Song C, Zhao $S$, et al (2017) Air pollution characteristics and their relation to meteorologica conditions during 20142015 in major Chinese cities. Environ Pollut 223, 484-96.

11. Tian G, Qiao Z, Xu X (2014) Characteristics of particulate matter (PM10) and its relationship with meteorological factors during 2001-2012 in Beijing. Environ Pollut 192, 266-74. 
12. Kim Oanh NT, Leelasakultum K (2011) Analysis of meteorology and emission in haze episode prevalence over mountain-bounded region for early warning. Sci Total Environ 409, 2261-71.

13. Setianto A, Triandini T (2013) Comparison of kriging and inverse distance weighted (IDW) interpolation methods in lineament extraction and analysis. $J S E$ Asian Appl Geol 5, 21-9.

14. Trang NH, Tripathi NK (2014) Spatial correlation analysis between particulate matter 10 (PM10) hazard and respiratory diseases in Chiang Mai province, Thailand. Int Arch Photogramm Remote Sens Spatial Inf Sci XL-8, 185-91.

15. Juneng L, Latif MT, Tangang F (2011) Factors influencing the variations of PM10 aerosol dust in Klang Valley, Malaysia during the summer. Atmos Environ 45, 4370-8.

16. Cheng N, Li Y, Cheng B, Wang X, Meng F,Wang Q, Qiu $Q$ (2018) Comparisons of two serious air pollution episodes in winter and summer in Beijing. $J$ Environ Sci 69, 141-54.

17. Hongthong A, Suma Y, Pasukphun N, Keawdounglek V (2017) Analysis of air quality impacts on human health using the geoinformatics application: Chiang Rai Province. App Envi Res 39, 25-32.

18. Li X, Ma Y, Wang Y, Liu N, Hong Y (2017) Temporal and spatial analyses of particulate matter (PM10 and PM2.5) and its relationship with meteorological parameters over an urban city in northeast China. Atmos Res 198, 185-93.

19. Zu Y, Huang L, Hu J, Zhao Z, Liu H, Zhang H, Ying Q, Chen M (2017) Investigation of relationships between meteorological conditions and high PM10 pollution in a megacity in the western Yangtze River Delta, China. Air Qual Atmos Health 10, 713-24.

20. Jo EJ, Lee WS, Jo HY, Kim CH, Eom JS, Mok JH, Kim $\mathrm{MH}$, Lee K, et al (2017) Effects of particulate matter on respiratory disease and the impact of meteorological factors in Busan, Korea. Respir Med 124, 79-87.

21. Sá E, Tchepel O, Carvalho A, Borrego C (2015) Meteorological driven changes on air quality over Portugal: a KZ filter application. Atmos Pollut Res 6, 979-89.

22. Csavina J, Field J, Félix O, Corral-Avitia AY, Sáez AE, Betterton E (2014) Effect of wind speed and relative humidity on atmospheric dust concentrations in semi-arid climates. Sci Total Environ 487, 82-90.

23. ul-Haq Z, Rana AD, Ali M, Mahmood K, Tariq S, Qayyum Z (2015) Carbon monoxide (CO) emissions and its tropospheric variability over Pakistan using satellite-sensed data. Adv Space Res 56, 583-95.

24. Lin YC, Lin CY, Lin PH, Engling G, Lin YC, Lan YY, Chang CWJ, Kuo TH, et al (2013) Influence of Southeast Asian biomass burning on ozone and carbon monoxid over subtropical Taiwan. Atmos Environ 64, 358-65.

25. Park K, Rhee TS (2015) Source characterization of carbon monoxide and ozone over the Northwestern Pacific in summer 2012. Atmos Environ 111, 151-60.

26. Giovanis E (2018) The relationship between teleworking, traffic and air pollution. Atmos Pollut Res 9,1-14.

27. Barbulescuab A, Barbes L (2017) Modeling the carbon monoxide dissipation in Timisoara, Romania. $J$ Environ Manage 204, 831-8.

28. Turalioglu S, Ocak FS (2008) Effect of meteorology on the atmospheric concentrations of traffice-related pollutants in Erzurum, Turkey. J Int Environ Appl Sci 3, 325-35.

29. Zhang H, Wang Y, Hu J, Ying Q, Hu XM (2015) Relationships between meteorological parameters and criteria air pollutants in three megacities in China. Environ Res 140, 242-54. 